Bazzan, J., Formoso, C.T., and Echeveste, M. 2020. "Use of Complaint Records of Maintenance Departments for Continuous Improvement." In: Tommelein, I.D. and Daniel, E. (eds.). Proc. $28^{\text {th }}$ Annual Conference of the International Group for Lean Construction (IGLC28), Berkeley, California, USA, doi.org/10.24928/2020/0099, online at iglc.net.

\title{
USE OF COMPLAINT RECORDS OF MAINTENANCE DEPARTMENTS FOR CONTINUOUS IMPROVEMENT
}

\author{
Jordana Bazzan ${ }^{1}$, Carlos Torres Formoso ${ }^{2}$, and Márcia Echeveste ${ }^{3}$
}

\begin{abstract}
Housebuilding companies are required to deal with customer complaints in the warranty period. Some of them have maintenance departments that make necessary repairs in existing buildings. Due to this service, companies accumulate records on the quality of projects, which can contribute to the understanding of occurrence defects and their causes, supporting continuous improvement. However, deficiencies in information management can make it difficult to use complaints records as a feedback source. The literature does not discuss solutions for managing information related to customer complaints, nor the use of performance metrics that can effectively provide feedback from quality problems identified. This study has two contributions: a classification structure for the types of defects identified from complaints, and indicators generated by fault tree analysis. The study was carried out in the maintenance department of a Brazilian housebuilding company. The evidence sources used were: complaint database analysis, discussion seminars, and interviews with the company representatives. The proposed solutions resulted in improvements regarding the structure and level of detail of the records. Also, the fault tree analysis made it possible to identify the most critical quality problems as well as to evaluate the level of impact of each one in project quality.
\end{abstract}

\section{KEYWORDS}

Quality, Continuous Improvement, Waste, Complaint, Fault Tree Analysis.

\section{INTRODUCTION}

The demand by construction clients for quality products and services is on the increase, who have become more aware of their rights regarding the quality of products and services (Öztaş et al. 2007; Picchi and Agopyan 1993). In Brazil, consumer rights are strongly supported by the Consumer Protection Code (Brazil 1990) and the Building Performance Standard (NBR 15575) (ABNT 2013). In this context, there is a growing number of lawsuits that have been decided in favor of costumers (Rohr et al. 2019).

Despite increased litigation, quality management systems deployed by contractors in Brazil are still ineffective, resulting in high rates of building defects (Berr 2016; Brito et al. 2011; Cupertino and Brandstetter 2015; Fantinatti 2008). The occurrence of defect

PhD Candidate, Building Innovation Research Unit (NORIE), Federal University of Rio Grande do Sul, Porto Alegre, jordanabazzan@gmail.com, orcid.org/0000-0003-0743-8630

2 Professor, Postgraduate Program in Civil Engineering, Federal University of Rio Grande do Sul (UFRGS), Porto Alegre, RS, Brazil, formoso@ufrgs.br, orcid.org/0000-0002-4772-3746

3 Professor, Postgraduate Program in Industrial Engineering (PPGEP), Universidade Federal do Rio Grande do Sul, Porto Alegre, echeveste@producao.ufrgs.br, orcid.org/0000-0003-1084-0495 
results in waste, high repair costs, and a negative impact on customer satisfaction and on company's brand (Milion et al. 2016; Mills et al. 2009; Rosenfeld 2009). According to Koskela et al. (2019), one reason for this scenario is the little attention provided by the ISO 9000 set of standards to the implementation of the continuous improvement principle. Only in the latest revision of those standards, in 2015, a less procedural approach for the Plan-Do-Check-Act cycle (PDCA) was adopted, emphasizing the application of that cycle at all managerial levels of organizations (Koskela et al. 2019). Koskela et al. (2019) also point out that in order to maintain and improve quality, companies need information and knowledge that can be obtained from real-world observations.

In the PDCA cycle, improvement opportunities must be identified, and corrective and preventive actions must be planned (ISO 9001:2015), and this can be supported by the analysis of customer complaints (Cavalcanti 2012). By dealing with customer complaints during the product warranty period, companies have the opportunity to obtain information on project quality. These records may be used to generate a database, which can aid the comprehension of common defects and their causes so as to provide feedback for future projects (Carneiro et al. 2016; Cavalcanti 2012; Cupertino and Brandstetter 2015).

However, customer complaint data are rarely fully explored by housebuilding companies, due to difficulties in managing this type of information (Cavalcanti 2012). Complaint data are often collected and stored without an adequate structure, generating inconsistent information, which provides little support to the implementation of improvements. Also, inconsistent quality indicators are generated due to those problems (Brito et al. 2011; Cupertino and Brandstetter 2015). Although some studies approached the use of complaint data, there is a gap in knowledge regarding how to structure information on defects so that it can be used for continuous improvement. Most studies developed so far are limited to a descriptive analysis of the frequency of different types of defects (Brito et al. 2011; Cupertino and Brandstetter 2015; Forcada et al. 2013, 2015).

This research aims to use the complaints records of the maintenance departments as a source of learning for continuous improvement in quality management systems of construction companies. Its main contributions are: (i) a classification structure of the defects to be used in the storage and analysis of complaint data; and (ii) a set of indicators related to building defects based on the use of Fault Tree Analysis (FTA).

\section{LITERATURE REVIEW}

\section{COMPLAINT}

When customers' expectations are not fulfilled or if they still feel unsatisfied, there are several forms of reaction, including making complaints to the company (Singh 1988). Thus, a complaint is a statement of unmet expectations and therefore an opportunity for the company to handle the customer frustrations to increase the level of satisfaction (Barlow and Moller 1996). According to Barlow and Moller (1996), companies do not like to hear complaints because they attribute to them a negative reputation of their own business. By contrast, consumer-focused companies usually encourage their clients to complain directly to their representatives (Barlow and Moller 1996; Fisher 1999) by considering a complaint as an opportunity for remedial action. In addition, this makes it possible the capture of relevant information to improve products and services (Fisher 1999).

In the real-estate market, customers often make complaints because product purchase value is high. Moreover, much importance is given to this purchase because a large part 
of the population makes a single purchase of this type of product in a lifetime (Barlow and Moller 1996).

\section{DEFECTS}

Several words can be used to describe the lack of quality in the literature, such as error, failure, defect, rework, or non-conformance. However, there is no consensus on these definitions in the academic world (Rausand and ØIen 1996). According to ISO 9000 (ABNT 2015), non-conformance is "the non-fulfilment of a requirement" and a defect is the non-fulfilment of a requirement related to an intended or specified use". However, Davis et al. (1989) considers that there is no practical difference between nonconformities and defects. Atkinson (1987) makes a distinction between failure, defined as a deviation from good practice, which may or may not be corrected before the delivery of the building, and a defect, understood as a performance deficit that manifests itself when the building is in operation. Watt (1999) supports this definition and points out that defect is an imperfection or deficiency in the function, performance, legal requirements or user requirements of a building and manifests itself within the structure, production, services or other facilities of the affected building. Finally, the term pathological manifestation is also commonly used in the construction industry to describe visible defects manifested in buildings, such as cracks, stains, detachments, among others (Alexandre 2008; Carraro and Fernando 2014; Gnipper 2010).

According to Josephson and Hammarlund (1999), the cause is the reason for the existence of a defect, and there may be a combination of several causes or a chain of causes associated with the occurrence of a defect. Causes of defects may be related to failures in design, execution, use of inappropriate materials, improper use or absent of maintenance (Rausand and ØIen 1996).

Chong and Low (2006) identified 18,704 defects recorded in reports from condominium managers in 74 projects. A large percentage $(60 \%)$ of causes of defects were associated to design problems, while only $4 \%$ were associated to maintenance failures. Brito et al. (2011) analysed a database of 6,956 complaints from users in 42 social housing projects, with occupancy times from 3 to 5 years. That study concluded that $61 \%$ of the records were related to design and construction defects, followed by maintenance defects $(29 \%)$ and user behaviour problems $(10 \%)$. Overall, those studies show that most of the defects identified in the use stage of projects can be associated with design and construction failures.

\section{FAULT TREE ANALYSIS}

Fault Tree Analysis (FTA) is a tool used for quality improvements, based on the analysis of failures and their causes (Freitas and Colosimo 1997). FTA is used to identify the causes of failures and to develop logical relationships between the most basic causes and the total system failure. This tool is represented by a diagram in which it is possible both to get an overview of the cause-effect relationships, and to calculate the risks of a system failing (Freitas and Colosimo 1997). The risks are quantified from the probability of occurrence of basic and top events. Therefore, the probability of the top event is calculated from the probabilities of the basic events, propagating them until the risk of failure for the top event is estimated (Abdelgawad and Fayek 2011).

FTA uses Boolean operators AND and OR to calculate probabilities. The AND operator is used to represent the logic that the upper event cannot occur unless all lower events occur, and the OR operator is used to represent the logic that the occurrence of any 
single event at the lower level is sufficient for the upper event to occurs. For the context of the construction industry, the OR operator is commonly used because only the occurrence of one type of defect is often sufficient for the building element or system to fail (Abdelgawad and Fayek 2011)

From FTA results, it is possible to identify the level of contribution that the occurrence of each basic event has on the system failure (Tian et al. 2013). Furthermore, by analyzing the incidence of failures together with Boolean operators, it is possible to determine the different probabilities and reasons that lead to system failure, with the aim of supporting decision making, and improving system reliability (Tian et al. 2013).

\section{RESEARCH METHOD}

This research study was carried out with the maintenance department of a Brazilian housebuilding company located in the Porto Alegre, Brazil. This is considered to be a leading company in this segment of the construction industry and is well-known for being very advanced in the implementation of Lean Production practices, including the Last Planner System, Visual Management, and material supply Kanban systems. This company has a Technical Assistance Department, which is in charge of dealing with complaints. A large database with complaint data has been created, which is used to trigger repair activities and provide feedback for future projects.

The main sources of evidence used in this investigation are: (i) analysis of the database, containing 5,628 records of complaints, between January 2017 and March 2018, related to thirty projects, during the warranty period; (ii) semi-structured interviews with the representatives from different areas: design, material supply, quality management, planning and cost estimating, and production management; and (iii) two seminars to discuss the results.

The defects reported by customers were categorized and organized according to a classification structure. This restructuring was necessary since there were too many categories of complaints, which were confusing and ambiguous, making it difficult to consistently analyze data.

The new structure was based on the definitions of "component", "elements" and "systems" made by NBR 15575 (ABNT 2013) and according to classifications found in previous studies on building defects (Berr 2016; Brito et al. 2011; Chong and Low 2006; Das and Chew 2011; Forcada et al. 2013; Georgiou 2010; Macarulla et al. 2013). This structure also considered the warranty period of building components, as established by NBR 15575 (ABNT 2013).

The category called "defect detailing" was also proposed in this structure. The importance of this classification was highlighted in the semi-structured interviews. Unlike other data sources, it is possible to collect data on defects with a higher level of detail during repair services, as the team in charge of that has to do an initial inspection of the defect. As an example, it is possible to check during the inspection the exact position of a crack. For some defect types, this type of classification has not been created, since it is not possible to obtain further details about defects based on visual inspection. The "defect detailing" category was created from specific characteristics of the defects reported in the literature and from reports found in the company's database.

Due to the limited number of records available for this investigation, the categories "component" and "defect detailing" were not used as variables in data analysis. As a suggestion, they should be considered in future studies if more data is available. 
Finally, data analysis was carried out using only the complaints records whose defect was caused by a design or construction failure, i.e, the responsibility for repairing the defect lies with the company. The analysis was performed and represented by using a fault tree analysis (FTA), allowing for the identification of the occurrence probability of the types of defects at the different levels, systems and elements of the projects. The probability of an event occurring is the ratio between favourable and possible results (Costa Neto 2002). In this investigation, favourable results refer to the frequency of occurrence of the fault type and, as possible results, the house number covered by warranty. Therefore, the warranty periods established for each type of fault was considered.

\section{RESULTS AND DISCUSSION}

\section{Defect Classification Structure}

The classification structure of the defect types was organized into six levels of detail, as shown in

Figure 1.

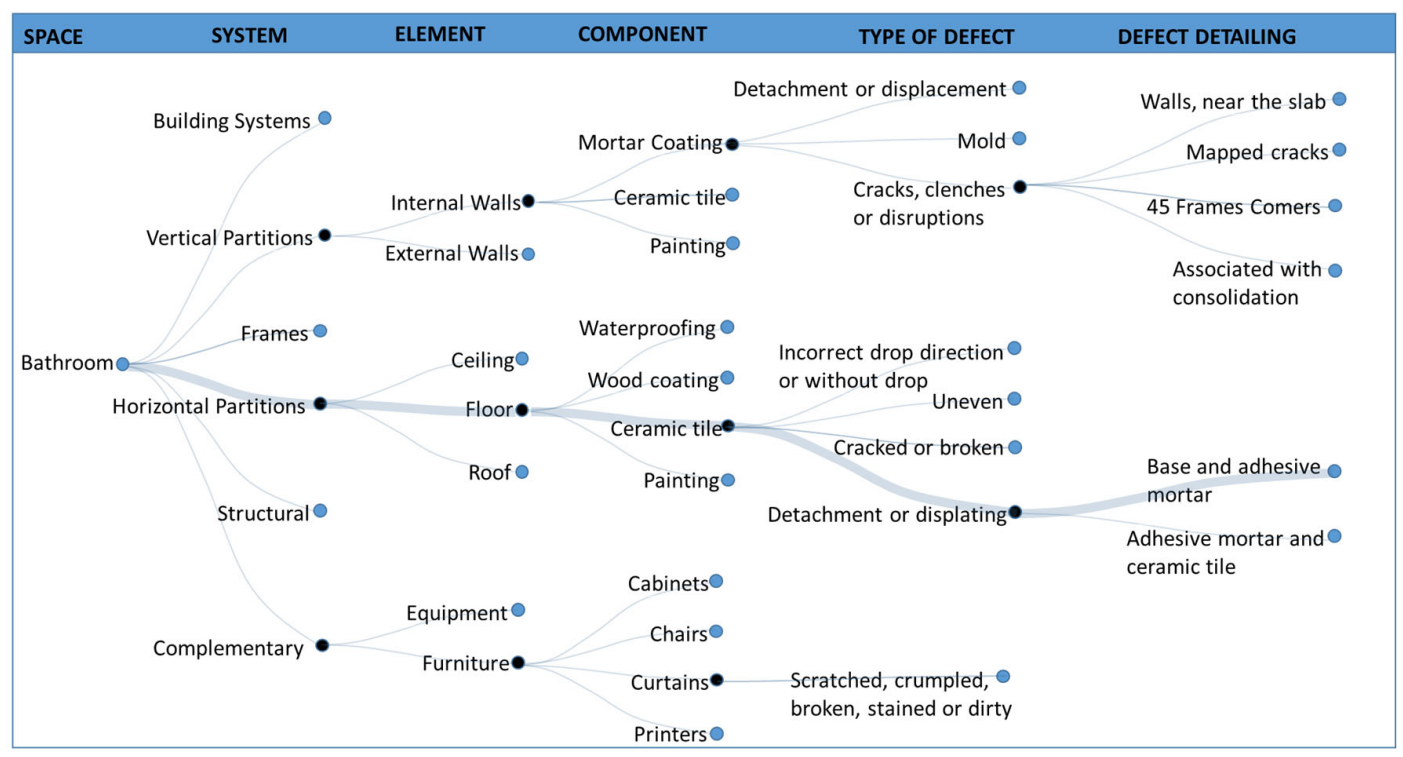

Figure 1: Defect classification structure

The first level refers to the environment (space) in which the defect is located such as bathroom, bedroom, kitchen and others. The following three levels refer to the "system", "element" and "component" of the building, while the fifth and sixth level refer to the description of the type of defect, "type of defect" and "defect detailing".

Six categories were proposed for the system level: building systems, frames, vertical partitions, horizontal partitions, structure and complementary. About the latter, it is composed of elements of the building, no less important, but which do not belong to the other categories of systems such as mailboxes, barbecue equipment, furniture installed in commercial projects, among others.

In Figure 1, an example of a defect reported by customers is presented. In this case, the detachment of the ceramic tile occurred, due to the loss of adherence between the 
substrate and the adhesive mortar. The defect was identified on the bathroom floor. It must be pointed out that the category "defect detail" adds information to the records, helping to identify the root causes of problems. In this example, the error in the specification or manufacturing ceramic materials can be discarded as the loss of adherence occurred between other components of the horizontal partitions. Based on that information, the company can hold detailed information for precise actions in the implementation of the company's process improvement.

In general, the proposed structure seeks to organize information about the defects hierarchically and logically. This allows an easy to choice between options with few alternatives at each level of information detail, in order to avoid having too many categories throughout the structure. Besides, the structure provides clear classification criteria, without ambiguities, mitigating possible data inconsistency analysis. Finally, levels of detailing of the information proposed can be used depending on the purpose of analysis, for example, the two lowest levels - the type of defect and defect detailing - can be used to investigate the causes of the problem, while the first level - system - can be used to support management decisions based on the records of systems that have shown low performance.

\section{SORTING OF COMPLAINTS RECORDS}

Due to failures in data collection, it was necessary to discard a large number of complaint records because they were inconsistent or difficult understanding: As shown in Figure 2a, $69.28 \%$ were considered valid records, while $30.72 \%$ were considered invalid. As an example, part of the records did not have enough information to allow classification of the defect, so they were not considered in the analysis. These discarded records are mostly a result of the lack of an adequate data collection structure.

(a)

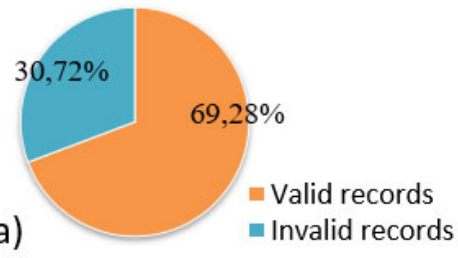

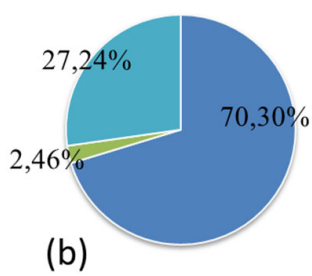

(b)
Records on construction defects

- Records on inadequate repair

- Records not related to design and construcion failures

Figure 2: Frequency of (a) records analysed (b) nature of valid records

Regarding valid complaint records (Figure 2b), 70,30\% are complaints of defects whose repair is the company's responsibility, named construction defects, while $27.24 \%$ of records deal with complaints on the defects that not related to design and construction defects. These are some examples this type of complaint: (i) occurrence of defects due to lack of maintenance (ii) defects generated by inadequate changes in the building; and,(iii) improper use of building components (such as irregular waste disposal in the sewage system, cleaning with too much water in non-waterproofed areas, and absence of ventilation causing moulds on surfaces). Finally, only $2,46 \%$ of records are related to inadequate repair services that have generated new complaints.

Although the first entail higher costs for the company due to the responsibility for repairing the defect, the other records types cannot be ignored as they represent around 
one-third of the number of calls demanded to the maintenance team. Therefore, these complaints should also be mitigated through feedback actions.

The results were presented at the seminars held with the participation of company representatives. They were surprised by the high number of complaints records on defects not related to design and construction defects. As a result, the maintenance department managers became much more interested in this type of information, as only complaints on construction defects were considered in the feedback practices carried out by the company.

\section{Probability of ocCurRence}

Figure 3 presents the fault tree containing the probabilities of failure of systems and elements. Frames, vertical partitions and building systems are the systems that contribute most to the failure of the set of projects, with $28.17 \%, 16.90 \%$ and $15.38 \%$, respectively, of probability of failure. For the frames system, if only the failures related to the window element were eliminated (23.88\% probability of failure), there would be a great impact on system performance, resulting in $4.29 \%$ probability of system failure. By contrast, the vertical partitions system demands improvement actions for both elements, internal and external walls.

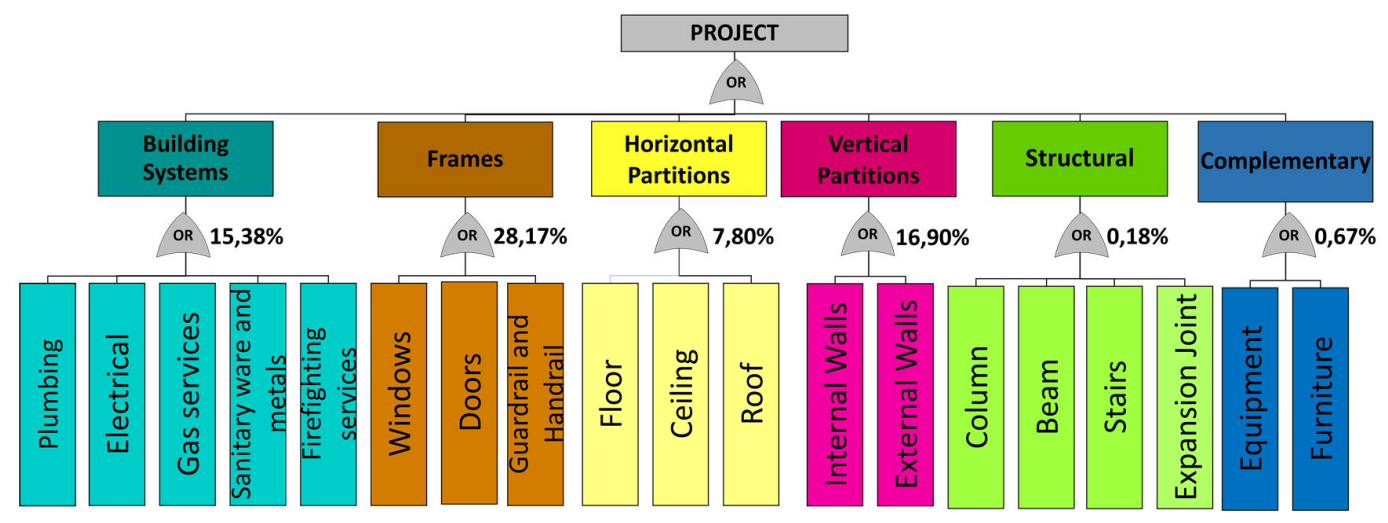

$6,14 \% \quad 6,07 \% 0,22 \% \quad 2,0 \% \quad 0,96 \% 23,88 \% 3,99 \% \quad 0,30 \% 7,35 \% \quad 0,22 \% 0,22 \% \quad 8,85 \% \quad 8,05 \% \quad 0,03 \% \quad 0,04 \% \quad 0,04 \% 0,07 \% 0,37 \% 0,30 \%$

Figure 3: Fault tree

The structural and complementary systems presented the lowest probabilities of failure, $0.18 \%$ and $0.67 \%$, respectively. Regarding the structural system, the low number of defects reported may be the result of the lack of knowledge of the customers about this system. Thus, the occurrence of defects in the structures may not be effectively identified from this source of data and other forms of post-occupation assessment should be considered by the construction companies.

The failures of the two most critical systems, frames and vertical partitions are discussed in more detail below.

\section{Vertical Partitions System}

Altogether, 111 complaints related to defects associated with "internal walls" were identified, in which 93 of them pertain to the type of defect "detachment or displacement". For this type of defect, there were 1251 residential units covered by the warranty period. Therefore, the probability of occurrence of this type of defect is $7.43 \%$. (Figure 4 ). 
Regarding "external walls", the most likely type of defect to occur is "infiltrations or leaks" with a $7.25 \%$ probability of occurrence.

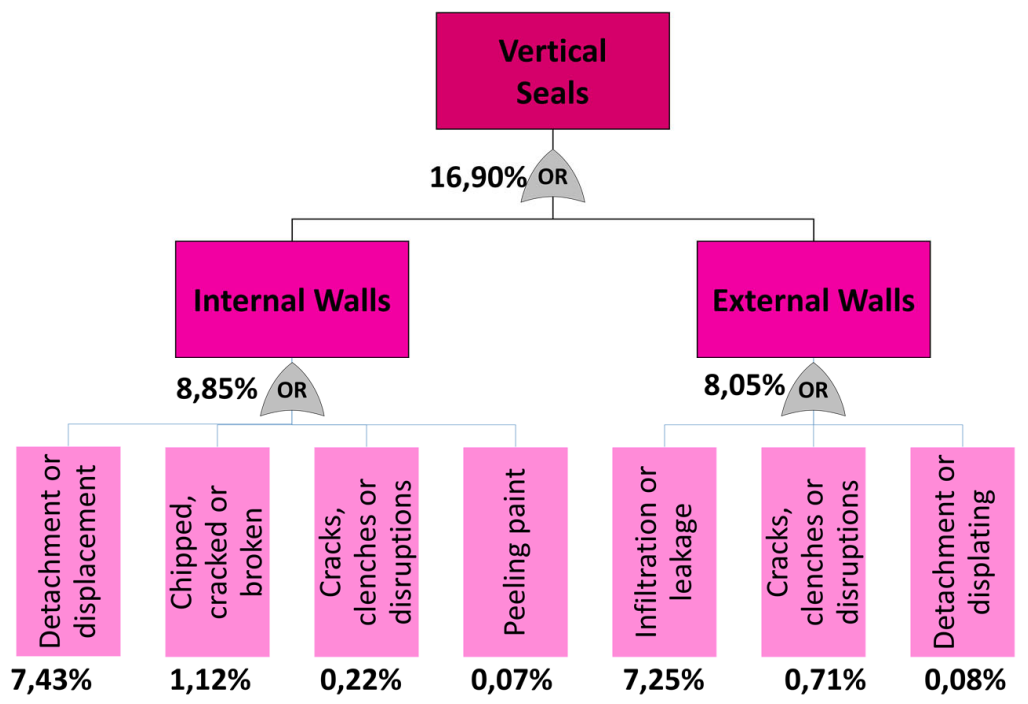

Figure 4: Vertical partitions fault tree

Based on the fault tree, if the occurrence of the type of fault "detachment or displacement", associated to the "internal walls", and the "infiltration or leakage", associated to the "external walls", were eliminated, there would be a $14.68 \%$ reduction in the probability of the "vertical partitions" failing. Therefore, these two defects represent a great impact on the system. Mitigating the occurrence of the other types of defects would result in minor reductions in the probability of failure of the elements and system.

During the discussion seminars, it was mentioned that the "detachment or displacement" failures were caused for two reasons: (i) incompatibility of the physical characteristics of the ceramic with the technique used to lay the tiles, and; (ii) loss of adhesion due to the high absorption of humidity of the tile during laying. By contrast, although the company identified the root causes of these failures, these were not registered, resulting in the loss of traceability of the causes and the solution adopted for different defects.

Finally, it was reported by the company that infiltrations in the external walls (façades) were caused by the use of single-layer mortar. This type of coating showed an inadequate performance, causing the entrance of moisture into the building.

The analysis of the fault tree could be more useful if more information is available to be analysed such as the root causes, as previously discussed, and information recorded at the level of "defects detailing", proposed in the classification structure. By doing that, combinations of possible causes could be analysed and the interaction behavior between them could be assessed, thus leading to a more accurate and complete assessment of the system as a whole.

\section{Frame System}

Figure 5 shows the probability of the defect types for the "frames" system together with the probability of the elements failing. There were 299 records of complaints regarding construction defects associated with the "windows" in which 177 of them refer to 
infiltrations. For this type of defect, there were 1352 residential units covered by the warranty period. Therefore, the probability of occurrence of this type of defect was $14.15 \%$. (Figure 5). Concerning doors, the most likely type of defect is the "components not working", such as locks and handles, with a $1.33 \%$ probability of occurrence.

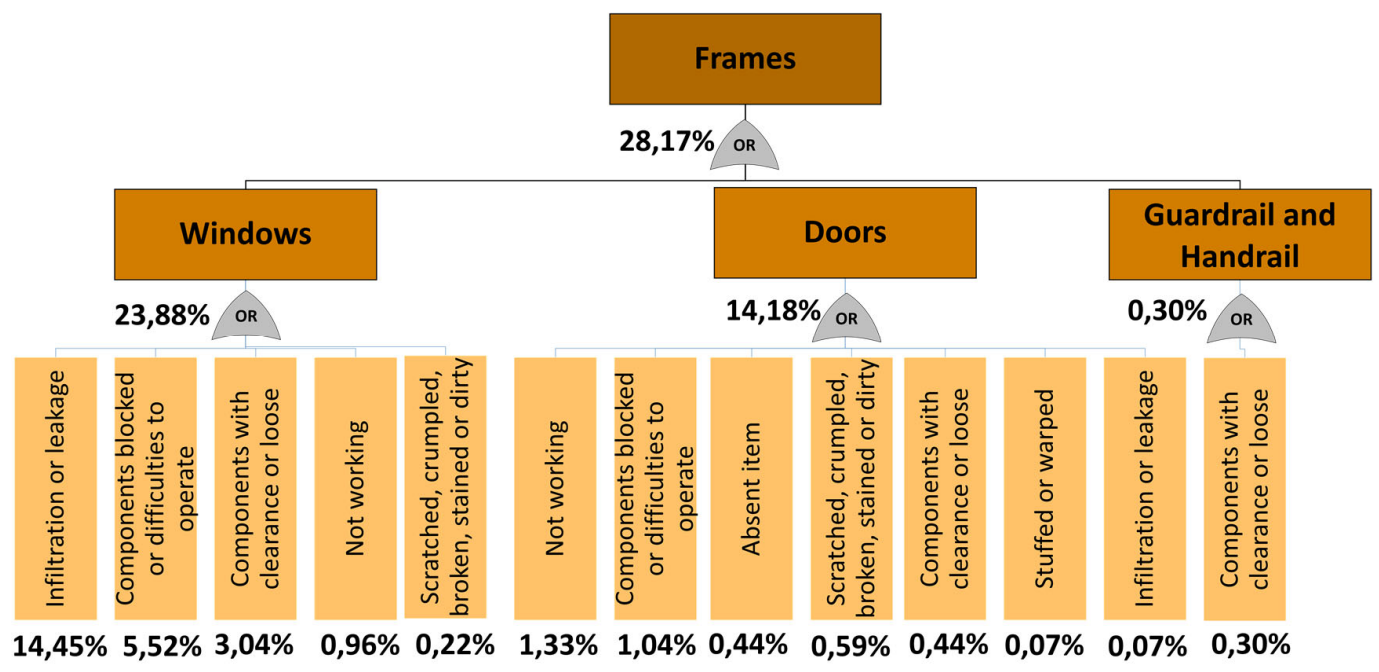

Figure 5: Frames fault tree

Based on the fault tree, if the infiltrations through the windows were eliminated, there would be a $14.45 \%$ reduction in the probability of the frame system failing. Therefore, this type of defect has a major impact on the system, while mitigating the occurrence of others, would represent less significant reductions in the probability of failure of the elements and system.

During the discussion seminars, it was mentioned that most of the infiltrations claimed by customers happened in the windows of a specific manufacturer, which was triggered to correct the faults. After the low performance of the supplier was identified, it was removed from the set of the company's suppliers.

\section{FINAL CONSIDERATIONS}

The recurrent quality problems observed in construction projects are often the result of the ineffective quality management. The implementation of process improvements can be supported by the analysis of complaint records. However, maintenance departments of housebuilding companies often face difficulties in managing effectively this type of information.

This research study has made two contributions: (i) a classification structure of the defects to be used in the registration of complaints; and (ii) indicators related to building defects based on the use of Fault Tree Analysis (FTA). The classification structure allows information on defects to be stored in an organized, complete and detailed way, making data collection more consistent, and allowing the generation of useful information for feedback purposes. One limitation of this paper was that the "component" and "defect detailing" categories were not considered in the analysis due to the limited number of records in the company's database so far.

Regarding data analysis, the indicators generated by the FTA made it possible to identify the most critical systems, elements and types of defects in the set of projects, and 
it was possible to evaluate the level of impact if they were eliminated. These indicators can help quality management systems during the implementation of process improvements.

As this is an ongoing study, a full analysis of this database will be made, considering all levels of the structure, as soon as more data is made available. This will make it possible to explore the full potential of FTA, by using more detailed information on causes and the solutions adopted for the problems. In addition, more sophisticated data analysis techniques, such as regression models can also be employed, making it possible to understand the impact of different variables on the formation of defects.

\section{REFERENCES}

Abdelgawad, M., and Fayek, A. R. 2011. "Fuzzy Reliability Analyzer: Quantitative Assessment of Risk Events in the Construction Industry Using Fuzzy Fault-Tree Analysis." ASCE, J. Constr. Eng. Manage., 137(4): 294-302. https://doi.org/10.1061/(ASCE)CO.1943-7862.0000285.

ABNT (Brazilian Association of Technical Standards). 2013. NBR 15575-1: Residential Buildings Up To Five Floors - Performance Part 1: General Requirements. Rio de Janeiro: ABNT.

ISO (International Organization for Standardization). 2015. Quality Management Principles. Geneva, Switzerland: ISO.

Alexandre, I. F. 2008. "Building pathologies in low cost housing projects with structural masonry: an analysis of the cause-effect relationship." M.Sc Thesis., Postgraduate Program in Civil Engineering, Federal University of Rio Grande do Sul, Porto Algre.

Atkinson, G. 1987. A century of defects. Building, 252, 54-55.

Barlow, J. and Moller, C. 1996. Customer Complaint? There's no better gift: using customer feedback as a strategic tool. São Paulo: Futura, 304.

Berr, L. R. 2016. "Evaluation method of construction quality in social housing units in the use step - technical analysis and perception by users." PhD Diss., Postgraduate Program in Civil Engineering, Federal University of Rio Grande do Sul, Porto Algre.

Brazil (Presidency of the Republic). 1990. Law n. 8.078, September 11, 1990. Provides consumer protection and other measures. Brasília, Distrito Federal: Brazil.

Brito, J. N. D. S., Formoso, C. T., and Echeveste, M. E. S. 2011. "Analysis of complaint data in social house-building projects: a study in the Residential Leasing Program." Amb. Constr., 11(4), 151-166. https://doi.org/10.1590/S1678-86212011000400011.

Carneiro, T. M., Cardoso, D. R., and Barros Neto, J. de P. 2016. "Proposal of model to improve feedback on projects of hydraulic and sanitary building systems." Rev. Prod., 16(4), 1285-1308. https://doi.org/10.14488/1676-1901.v16i4.2317.

Carraro, C. L., and Fernando, D. J. 2014. "Guidelines for the prevention of pathological manifestations in Social Housing." Amb. Constr., 14(2), 125-139. https://doi.org/10.1590/S1678-86212014000200009.

Carretero-Ayuso, M. J., Moreno-Cansado, A., and García-Sanz-Calcedo, J. 2020. "Occurrence of faults in water installations of residential buildings: An analysis based on user complaints." J. Build. Eng., 27, 100958. https://doi.org/10.1016/j.jobe.2019.100958.

Cavalcanti, G. C. B. 2012. "Procedures for technical assistance in constructions of residencial buildings." M.Sc Thesis., Technological Research Institute of the State of São Paulo, São Paulo. 
Chong, W.-K., and Low, S.-P. 2006. "Latent Building Defects: Causes and Design Strategies to Prevent Them." ASCE, J. Perform. Constr. Fac., 20(3): 213-221. https://doi.org/10.1061/(ASCE)CO.0887-3828(2006)20:30(213).

Costa Neto, P. L. de O. 2002. Calculation of Probabilities - summary. Statistic, São Paulo: Edgard Blucher, 229.

Cupertino, D., and Brandstetter, M. C. G. de O. 2015. "Proposal for a post-work management tool based on the records of technical assistance requests." Amb. Constr., 15(4), 243-265. https://doi.org/10.1590/s1678-86212015000400049.

Das, S., and Chew, M. Y. L. (2011). "Generic Method of Grading Building Defects Using FMECA to Improve Maintainability Decisions." ASCE, J. Perform. Constr. Fac., 25(6): 522-533. https://doi.org/10.1061/(ASCE)CF.1943-5509.0000206.

Davis, K., Ledbetter, W. B., and Burati, J. L. 1989. "Measuring design and construction quality costs." ASCE, J. Constr. Eng. Manage., 115(3): 385-400. https://doi.org/10.1061/(ASCE)0733-9364(1989)115:3(385).

Fantinatti, P. A. P. 2008. "Knowledge management actions in the construction sector: evidencies from a construction company's maintenance." M.Sc Thesis., Faculty of Civil Engineering and Architecture, Campinas State University, Campinas, São Paulo.

Fisher, J. E., Garret, D. E., Arnold, M. J., and Ferris, M. E. 1999. "Dissatisfied consumers who complain to the Better Bussiness Bureau." J. Consum. Mark., 16(6), 576-589. https://doi.org/10.1108/07363769910297515.

Forcada, N., Macarulla, M., Gangolells, M., and Casals, M. 2015. "Handover defects: Comparison of construction and post-handover housing defects." Build. Res. Inf., 44(3), 279-288. https://doi.org/10.1080/09613218.2015.1039284.

Forcada, N., Macarulla, M., Gangolells, M., Casals, M., Fuertes, A., and Roca, X. 2013. "Posthandover Housing Defects: Sources and Origins." ASCE, J. Perform. Constr. Fac., 27(6): 756-762. https://doi.org/10.1061/(ASCE)CF.1943-5509.0000368.

Freitas, M. A., And Colosimo, E. A. 1997. Reliability: analysis of failure time and accelerated life testing. Belo Horizonte: Christiano Ottoni Foundation, 309.

Georgiou, J. 2010. "Verification of a building defect classification system for housing." Struct. Surv., 28(5), 370-383. https://doi.org/10.1108/02630801011089164.

Gnipper, S. F. 2010. "Guidelines for the formulation of a hierarchized method for investigation of building plumbing and drainage systems pathologies." M.Sc Thesis., Faculty of Civil Engineering and Architecture, Campinas State University, Campinas, São Paulo.

Josephson, P. E., and Hammarlund, Y. 1999. "The causes and costs of defects in construction A study of seven building projects." Automat. Constr., 8(6), 681-687. https://doi.org/10.1016/s0926-5805(98)00114-9.

Koskela, L., Tezel, A., and Patel, V. 2019. "Theory of Quality Management: Its Origins and History." Proc. 27th Annual Conference of the International Group for Lean Construction (IGLC), 1381-1390. Dublin, Ireland.

Macarulla, M., Forcada, N., Casals, M., Gangolells, M., Fuertes, A., and Roca, X. 2013. "Standardizing housing defects: classification, validation, and benefits." $A S C E, J$. Constr. Eng. Manage., 139(8): https://doi.org/968-976. 10.1061/(ASCE)CO.19437862.0000669 .

Milion, R. N., Alves, T. da C. L., and Paliari, J. C. 2016. "Impacts of residential construction defects on customer satisfaction." Int. J. Build. Pathol. and Adapt., 35(3), 218-232. https://doi.org/10.1108/IJBPA-12-2016-0033. 
Mills, A., Love, P. E., and Williams, P. 2009. "Defect Costs in Residential Construction." ASCE, J. Constr. Eng. Manage., 135(1): 12-16. https://doi.org/10.1061/(ASCE)07339364(2009)135:1(12).

Öztaş, A., Güzelsoy, S. S., and Tekinkuş, M. 2007. "Development of quality matrix to measure the effectiveness of quality management systems in the Turkish construction industry." Build. $\quad$ Environ., 42(3), 1219-1228. https://doi.org/10.1016/j.buildenv.2005.12.017.

Picchi, F. A., and Agopyan, V. 1993. Quality Systems in Building Construction. Technical Bulletin. Polytechnic School of University of São Paulo, São Paulo.

Rausand, M., and ØIen, K. 1996. "The basic concepts of failure analysis." Reliab. Eng. Syst. Safe., 53(1), 73-83. https://doi.org/10.1016/0951-8320(96)00010-5.

Rohr, D., Costella, M. F., And Costella, M. de M. 2019. "Study of jurisprudences related to the performance standard." Proc. XI Simpósio Brasileiro de Gestão e Economia da Construção / VIII Encuentro Latino americano de Gestión y Economía de la Construcción, ANTAC. Londrina, Brazil.

Rosenfeld, Y. 2009. "Cost of quality versus cost of non-quality in construction: The crucial balance." Constr. Manage. Econ, 27(2), 107-117. http://dx.doi.org/10.1080/01446190802651744.

Singh, J. 1988. "Consumer Complaint Intentions and Behavior: Definitional and Taxonomical Issues." J. Mark., 52(1), 93-108. http://dx.doi.org/10.2307/1251688.

Tian, H., Yijin Huang, He, J., Liu, P., and Qu, W. 2013. "Application of Fault Tree Analysis in the Reliability Analysis of Oil-Gas Long Pipeline." ASCE, J. Water Res. Pl., 136(5): 1436-1447. https://doi.org/10.1061/9780784412619.147.

Watt, D. 1999. Building Pathology Principles and Practice. UK: Wiley-Blackwell. 